\title{
The natural history of hypertrophic cardiomyopathy
}

\author{
Camillo Autore* and Maria Beatrice Musumeci
}

Department of Clinical and Molecular Medicine, Sapienza University of Rome, Rome, Italy

\section{KEYWORDS}

Hypertrophic cardiomyopathy; Natural history;

Mortality;

Prognosis;

Management

\begin{abstract}
In the early years of the disease recognition, hypertrophic cardiomyopathy (HCM) was viewed as an ominous disease with unfavourable prognosis and with an annual mortality between $4 \%$ and $6 \%$. At that time, $73 \%$ of the patients reported in the literature came from only two referral centres. With the introduction of echocardiography, our understanding of HCM has improved and non-selected patient populations were assembled in several centres. A more benign prognostic profile was documented with an annual mortality rate of $1.5 \%$ or less. In the 2000 s, important therapeutic interventions further improved the prognosis of patients with HCM: implantable-cardioverter defibrillator for prevention of sudden death, heart transplantation for treatment of severe refractory heart failure, and an extensive treatment with myectomy for relief of left ventricular outflow tract gradient. The natural history of HCM has changed substantially with contemporary treatment achieving an annual mortality rate less than $1 \%$ with extended longevity and a greatly improved quality of life.
\end{abstract}

The first contemporary account of the cardiac disease that we know as hypertrophic cardiomyopathy (HCM) is that by Donald Teare (a British pathologist and coroner in London) who reported asymmetric septal hypertrophy in eight patients. ${ }^{1}$ Notably, in that single communication, he masterfully described the pathophysiological markers (myocardial hypertrophy with myocyte disarray, small vessel disease with ischaemia and fibrosis), the clinical consequences (effort dyspnoea, palpitations, chest pain, syncope), and the most threatening and unpredictable complication of the disease, sudden cardiac death (SCD), mainly in the young (7 out of 8 patients had died suddenly). ${ }^{2}$

In the 1960s, a number of studies in literature reported patients evaluated with cardiac catheterization who developed intraventricular pressure gradient without an anatomical cause that could justify subaortic obstruction. At that time, HCM was called idiopathic hypertrophic subaortic stenosis (IHSS).

In 1968, the Braunwald group at the National Institutes of Health described the natural history of a large (at that time) population of 126 patients with IHSS. ${ }^{3}$ During a mean

*Corresponding author. Email: camillo.autore@uniroma1.it follow-up of about 3 years, 10 patients died, 6 of SCD and 4 due to progressive heart failure. The New York Heart Association (NYHA) functional class at first evaluation appeared to be an important prognostic index: $1 / 40$ (2.5\%) died among patients diagnosed in NYHA I, while 4/16 (25\%) died among those diagnosed in NYHA III/IV. On the other side of the ocean, in London, the Goodwin group at the Hammersmith Hospital published a study on the clinical course and prognosis of 85 patients with hypertrophic obstructive cardiomyopathy. ${ }^{4}$ In the analysis of a 4-years mean follow-up, 12 patients died, 6 of SCD (all young, with a mean age at death of 25 years) and 6 after surgery (myectomy); 12 patients experienced worsening of symptoms with progression to advanced NYHA functional class III/IV. At this time, HCM is viewed as an ominous disease with an unfavourable prognosis and with an annual mortality between $4 \%$ and $6 \%$.

In the 1970s, with the introduction of non-invasive imaging of the disease, represented by echocardiography, the diagnostic definition of the disease changes substantially: many non-obstructive forms of HCM were identified, allowing a more actual morphological spectrum of the disease, and the term HISS was replaced with HCM. New patients cohort are assembled, however still from referral centres. In a retrospective analysis of the clinical course of $254 \mathrm{HCM}$ 
patients, ${ }^{5}$ during a mean follow-up of 6 years, 58 patients died, 32 died suddenly and 38 died of sudden death or heart failure. The combination of young age at diagnosis, syncope, family history of HCM and sudden death, and severe functional limitation appeared to be the strongest predictors of sudden death. The annual mortality is higher where the diagnosis is made in adolescence $(5.9 \%)$; lower in subjects diagnosed after 15 years $(2.5 \%)$. These data still came from the above-mentioned Hammersmith Hospital in London, but the numbers are slightly changing and different classes of patients are now identified with different prognostic profiles.

We must wait until 1989 when, in a brilliant study, ${ }^{6}$ Spirito et al. actually challenged the prognostic paradigm of HCM. The authors made an analysis of the clinical course of $\mathrm{HCM}$ as described in 78 studies published in the last 5 years and compared it to that of 25 patients enrolled in their institution. During an average follow-up of 4.4 years, none of these last patients died or underwent a clinical deterioration. The authors underlined that $73 \%$ of patients reported in the literature came from only two referral centres and that $96 \%$ of patients with moderate-severe symptoms reported in the literature came from one of the same two referral institutions. The conclusions of the study clearly sounded like something new: 'The natural history of hypertrophic cardiomyopathy may be more benign than can be deduced from published studies'. The HCM clinical and scientific community had to move on.

The 1990s were characterized by several sizeable studies of HCM, largely from territorial or regional cohorts. Due to these 'unselected' samples of patient population, a more complete description of the great morphological and clinical heterogeneity of HCM and a more realistic view of its natural course was achieved. ${ }^{7}$ One of the most important studies came from Italy, on a cohort of $202 \mathrm{HCM}$ patients from the Tuscany region. ${ }^{8}$ During a mean follow-up of 10 years, 13 patients died, 11 due to heart failure and 2 to sudden death, amounting an annual cardiac mortality of $0.6 \%$ and that due to sudden cardiac death 'was only' $0.1 \%$. A retrospective investigation published on a regional cohort of the USA came to the same results and conclusions. ${ }^{9}$ In a mean follow-up of 8 years, the annual mortality of HCM was much lower than that reported in past years, about $1.5 \%$ or less, and survival, in the subset of patients diagnosed in adulthood, not substantially different from that of the general population. The old prognostic paradigm of the HCM has been superseded.

From the year 2000, several papers were aimed to describe the epidemiology and prognosis of some clinical aspects and complications of HCM, in larger and unselected cohorts. A general consensus has grown up that the complications encountered in patients with HCM walk along separate and relatively independent pathways, where, beside a great proportion of patients (around 60\%) that has a stable course without (or with minor) complications, we can distinguish four subgroups characterized by (i) a high risk of sudden death, (ii) progressive symptoms of heart failure with severe functional limitation associated with chest pain and, usually, in the presence of a preserved systolic function, (iii) end-stage phase of the disease with ventricular remodelling and systolic dysfunction; and (iv) atrial fibrillation (AF) with the complication of the embolic stroke. $^{10}$

In the year 2003, more than 40 years since the initial description of HCM, we had the first definite demonstration that the clinical course of HCM is less favourable in patients with the obstructive form of the disease. ${ }^{11}$ In a prospective population of $>1000 \mathrm{HCM}$ patients, $25 \%$ of whom with a gradient ( $>30 \mathrm{mmHg}$ in resting conditions) in left ventricular (LV) outflow tract, obstruction was independently associated with progressive symptoms of heart failure and $\mathrm{HCM}$-related death. Hypertrophic cardiomyopathy with obstruction is a more serious form of the disease with a worse prognosis.

Moreover, among patients with the non-obstructive form of the disease, a small subset may progress to the endstage phase of HCM, characterized by LV systolic dysfunction (ejection fraction less than 50\%), LV wall thinning and chamber enlargement, and progressive symptoms of heart failure. End-stage HCM is associated with worse outcomes, with a mortality rate $11 \%$ per year and is a sudden death risk factor. ${ }^{12}$

In more recent reports, another adverse clinical pathway has been described in those HCM patients who develop an apical aneurysm (up to $5 \%$ of cases). This unfavourable evolution of the disease, to whose identification cardiac magnetic resonance has given an important contribution, is accompanied by an elevated risk of death, mainly SCD, arrhythmias, and cardioembolic events, with a three times higher risk of disease-related complications compared to patients without an aneurysm. ${ }^{13}$

The identification and characterization of these distinct adverse clinical courses of HCM prompted the cardiologist to prepare the appropriate treatment strategies to counteract the outcomes in terms of morbidity and mortality. Since 2000, new strategies have developed for the treatment of patients with $\mathrm{HCM}$ as well other therapeutic options received a new impulse.

The implantable-cardioverter defibrillator (ICD) is able to stop fatal arrhythmias and will prove effective in preventing sudden death both in the adult population $(10 \%$ of interventions/year in secondary prevention and $4 \%$ of interventions in primary prevention $)^{14}$ and in children. ${ }^{15}$ The ICD has changed the natural history of many HCM patients.

Along the prognostic pathway characterized by severe refractory heart failure, heart transplantation (HT) has progressively become the definitive option in HCM patients who have advanced end-stage disease with the power of extending life. In addition, post-transplant survival rates of HCM patients demonstrated to be more favourable than those observed in patients with ischaemic cardiomyopathy. ${ }^{16}$ In this way, also HT contributed to modify the natural history of HCM and the life expectancy of patients.

Lastly, after the publication of the results from two different referral centres for surgery in HCM (Rochester and Toronto), showing that the surgical relief of obstruction in the LV outflow tract can modify the survival of patients, ${ }^{17,18}$ septal myectomy gained a new impulse, especially when compared with the previous 30 years. The surgical technique was enriched with complementary interventions compared to the traditional simple incision of the basal septal bulge (myotomy) and muscle excision 
(myectomy), and the operative mortality has fallen from an unacceptable $6 \%$ to a value less than $1 \%$ in centres of excellence, with stable improvement of symptoms on late follow-up. The new impulse for septal myectomy has represented an important step forward in the reduction of HCM morbidity and mortality. In selected patients with obstructive HCM (advanced age, those at an unacceptably high surgical risk for important comorbidities) alcohol septal ablation, a technique introduced in the late 1990, is now a reasonable alternative to surgery, providing symptomatic improvement and a good long-term survival. ${ }^{19}$

Finally, we have entered the contemporary era and, based on the above-mentioned progress on our understanding of the clinical spectrum HCM and on a targeted treatment strategies, a new vision of the natural history of HCM has been proposed, far from that of an ominous disease with high mortality and scarce resources to manage it. Hypertrophic cardiomyopathy has become a 'contemporary treatable disease' with a mortality rate less than $1 \%$ and with a greatly improved quality of life. ${ }^{20}$ Heart failurerelated death is the most frequent modality of death and SCD is more common in young patients less than 30 years old.

Certainly, the clinical as well as the psychological perspective of the disease has changed and patients can be reassured on the course of the disease and on the potential of several interventions to face its complications and to ameliorate the quality of life.

However, it is not all roses and a note of caution is required. Although the natural history of patients with HCM has dramatically changed into a more benign 'unnatural history' with contemporary treatment and extended longevity, we do not have yet a cure for HCM. Biologically, the disease phenotype progresses over time in the same way as it did 60 years ago. Accordingly, with this point of view, less enthusiastic results, based on a longitudinal observation of more than 4500 patients, are reported in the SHaRe registry. ${ }^{21}$ The analysis of data shows that the cumulative burden of HCM remains considerable in terms of morbidity, mainly characterized by heart failure and AF, especially in patients diagnosed of younger age and in those with sarcomere mutations. Furthermore, we must consider not only the burden of the disease but also how and to what extent the important therapeutic interventions put in the field to prolong survival (ICD, myectomy, HT) can impact on the patient's lives, by themselves or by their potential complications. Crucial advances are then needed to further improve the clinical care of HCM patients, developing therapies with the aim to prevent the phenotypic progression of the disease and its adverse consequences.

In conclusion, the natural history of HCM is the story of several natural histories of patients with the disease over the last 60 years, dictated by our changing knowledge of the disease and by the progressive improvement of treatment strategies. The actual frame shows a natural clinical course of the disease that has turned into an unnatural and more benign course. Conversely, we have not yet been able to intervene on the primary causes of the disease and modify the biological course of HCM.

Conflict of interest: none declared.

\section{References}

1. Teare D. Asymmetrical hypertrophy of the heart in young adults. $\mathrm{Br}$ Heart J 1958;20:1-8.

2. McKenna WJ, Sen-Chowdhry S. From Teare to the present day: a fifty year odyssey in hypertrophic cardiomyopathy, a paradigm for the logic of the discovery process. Rev Esp Cardiol 2008;61:1239-1244.

3. Frank S, Braunwald E. Idiopathic hypertrophic subaortic stenosis. Clinical analysis of 126 patients with emphasis on the natural history. Circulation 1968;37:759-788.

4. Swan DA, Bell B, Oakley CM, Goodwin J. Analysis of symptomatic course and prognosis and treatment of hypertrophic obstructive cardiomyopathy. Br Heart J 1971;33:671-685.

5. McKenna W, Deanfield J, Faruqui A, England D, Oakley C, Goodwin J. Prognosis in hypertrophic cardiomyopathy: role of age and clinical, electrocardiographic and hemodynamic features. Am J Cardiol 1981; 47:532-538

6. Spirito P, Chiarella F, Carratino L, Berisso MZ, Bellotti P, Vecchio C. Clinical course and prognosis of hypertrophic cardiomyopathy in an outpatient population. N Engl J Med 1989;320:749- 755.

7. Maron BJ, Spirito P. Impact of patient selection biases on the perception of hypertrophic cardiomyopathy and its natural history. Am J Cardiol 1993; 72:970-972.

8. Cecchi F, Olivotto I, Montereggi A, Santoro G, Dolara A, Maron BJ. Hypertrophic cardiomyopathy in Tuscany: clinical course and outcome in an unselected regional population. J Am Coll Cardiol 1995; 26:1529-1536.

9. Maron BJ, Casey SA, Poliac LC, et al. Clinical course of hypertrophic cardiomyopathy in a regional United States cohort. JAMA 1999;281: 650-655.

10. Maron BJ, McKenna WJ, Danielson GK, Kappenberger LJ, Kuhn HJ, Seidman CE, Shah PM, Spencer WH, Spirito P, Ten Cate FJ, Wigle ED, Vogel RA, Abrams J, Bates ER, Brodie BR, Danias PG, Gregoratos G, Hlatky MA, Hochman JS, Kaul S, Lichtenberg RC, Lindner JR, O'rourke RA, Pohost GM, Schofield RS, Tracy CM, Winters WL, Klein WW, Priori SG, Alonso-Garcia A, Blomström-Lundqvist C, De Backer G, Deckers J, Flather M, Hradec J, Oto A, Parkhomenko A, Silber S, Torbicki A. American College of Cardiology/European Society of Cardiology clinical expert consensus document on hypertrophic cardiomyopathy. J Am Coll Cardiol 2003;42:1687-1713.

11. Maron MS, Olivotto I, Betocchi S, Casey SA, Lesser JR, Losi MA, Cecchi F, Maron BJ. Effect of left ventricular outflow tract obstruction on clinical outcome in hypertrophic cardiomyopathy. $N$ Engl $J$ Med 2003;348:295-303.

12. Harris KM, Spirito P, Maron MS, Zenovich AG, Formisano F, Lesser JR, Mackey-Bojack S, Manning WJ, Udelson JE, Maron BJ. Prevalence, clinical profile, and significance of left ventricular remodeling in the end-stage phase of hypertrophic cardiomyopathy. Circulation 2006; 114:216-225.

13. Rowin EJ, Maron BJ, Haas TS, Garberich RF, Wang W, Link MS, Maron MS. Hypertrophic cardiomyopathy with left ventricular apical aneurysm: implications for risk stratification and management. J Am Coll Cardiol 2017;69:761-773.

14. Maron BJ, Spirito P, Shen W-K, Haas TS, Formisano F, Link MS, Epstein AE, Almquist AK, Daubert JP, Lawrenz T, Boriani G, Estes NAM, Favale S, Piccininno M, Winters SL, Santini M, Betocchi S, Arribas F, Sherrid MV, Buja G, Semsarian C, Bruzzi P. Implantable cardioverter defibrillators and prevention of sudden cardiac death in hypertrophic cardiomyopathy. JAMA 2007;298:405-412.

15. Maron BJ, Spirito P, Ackerman MJ, Casey SA, Semsarian C, Estes NAM, Shannon KM, Ashley EA, Day SM, Pacileo G, Formisano F, Devoto E, Anastasakis A, Bos JM, Woo A, Autore C, Pass RH, Boriani G, Garberich RF, Almquist AK, Russell MW, Boni L, Berger S, Maron MS, Link MS. Prevention of sudden cardiac death with implantable cardioverter-defibrillators in children and adolescents with hypertrophic cardiomyopathy. J Am Coll Cardiol 2013;61:1527-1535.

16. Maron MS, Kalsmith BM, Udelson JE, Li W, DeNofrio D. Survival after cardiac transplantation in patients with hypertrophic cardiomyopathy. Circ Heart Fail 2010;3:574-579.

17. Ommen SR, Maron BJ, Olivotto I, Maron MS, Cecchi F, Betocchi S, Gersh BJ, Ackerman MJ, McCully RB, Dearani JA, Schaff HV, Danielson GK, Tajik AJ, Nishimura RA. Long-term effects of surgical septal myectomy on survival in patients with obstructive hypertrophic cardiomyopathy. J Am Coll Cardiol 2005;46:470-476. 
18. Woo A, Williams WG, Choi R, Wigle ED, Rozenblyum E, Fedwick K, Siu $\mathrm{S}$, Ralph-Edwards A, Rakowski H. Clinical and echocardiographic determinants of long-term survival after surgical myectomy in obstructive hypertrophic cardiomyopathy. Circulation 2005;111:2033-2041.

19. Batzner A, Pfeiffer B, Neugebauer A, Aicha D, Blank C, Seggewiss H. Survival after alcohol septal ablation in patients with hypertrophic obstructive cardiomyopathy. J Am Coll Cardiol 2018;72:3087-3094.

20. Maron BJ, Rowin DJ, Casey SA, Maron MS. How hypertrophic cardiomyopathy became a contemporary treatable genetic disease with low mortality shaped by 50 years of clinical research and practice. JAMA Cardiol 2016;1:98-105.

21. Ho CY, Day SM, Ashley EA, Michels M, Pereira AC, Jacoby D, Cirino AL, Fox JC, Lakdawala NK, Ware JS, Caleshu CA, Helms AS, Colan SD, Girolami F, Cecchi F, Seidman CE, Sajeev G, Signorovitch J, Green EM, Olivotto I; For the SHaRe Investigators. Genotype and lifetime burden of disease in hypertrophic cardiomyopathy: insights from the Sarcomeric Human Cardiomyopathy Registry (SHaRe). Circulation 2018;138:1387-1398. 